\title{
Acute Myeloid Leukemia with Trisomy 8
}

National Cancer Institute

\section{Source}

National Cancer Institute. Acute Myeloid Leukemia with Trisomy 8. NCI Thesaurus. Code C162775.

An acute myeloid leukemia with trisomy 8 . Trisomy 8 is one of the most frequent occurring cytogenetic abnormalities in acute myeloid leukemia. It is grouped as intermediate risk in cytogenetic classifications of acute myeloid leukemia. 